Original Article

\title{
Antibiotic Sensitivity and Evaluation of Plasmid Profile of Major Foodborne Pathogens
}

\author{
Ibikunle Ibitayo Anibijuwon ${ }^{1}$, Ifeoluwa Deborah Gbala², Jumai Adeola Abioye ${ }^{3}$, Paul Oluwaseun \\ Ogunlade ${ }^{4}$ \\ Lecturers $^{1,3}$, Postgraduate Student ${ }^{2}$, Graduate Student ${ }^{4}$,Department of M icrobiology, Faculty of Life Sciences, University of \\ Ilorin, Ilorin, Nigeria.
}

*Corresponding Author : Ibikunle Ibitayo Anibijuwon, Lecturer, Department of M icrobiology, Faculty of Life Sciences, University of Ilorin, Ilorin, Nigeria. E-mail : kunledoexploit@gmail.com, kunledoexploit@unilorin.edu.ng.

Received : 21.03.2016

Review Completed : 01.10.2016

Accepted

: 02.11 .2016

Keywords : Antibiotics,

Resistance, Susceptibility, Plasmid

\begin{tabular}{|c|}
\hline Access this article online \\
\hline Quick Response Code \\
\hline
\end{tabular}

\begin{abstract}
This study revealed the reason behind the antibiotics resistance of isolated food-borne pathogens through their susceptibility testing to various antibiotics of choice. The results of the study revealed that resistance of the bacteria isolates which are Streptococcus sp. Staphylococcus aureus, Proteus vulgaris, Shigella sp., Escherichia coli, Pseudomonas aeruginosa, Bacillus sp. to different antibiotics varies and differs considerably. For instance, Pseudomonas aeruginosa showed resistance to Amoxicillin, Augmentin, Gentamicin and Tetracycline. Staphylococcus sp. isolated showed multiple resistances to Cloxacillin, Erythromycin, Amoxicillin, Augmentin and Gentamicin. Proteus vulgaris showed multiple resistances to five antibiotics in-vitro which are Augmentin, Nitrofurantoin, Amoxicillin, Cotrimoxazole and Nalidixic. The seven isolates were then assayed for plasmid profiling by agarose gel electrophoresis. All the isolates has plasmid with varying sizes of between $9-21 \mathrm{~kb}$. Further conjugativestudy will reveal more reason behind the resistance.
\end{abstract}

\section{Introduction}

Food borne disease arises by the consumption of contaminated foods or beverages. Many different pathogens can contaminate foods, which have given rise to so many different food borne infections ${ }^{[13]}$.

Also, poisonous chemicals, or other harmful substances can cause food borne diseases if they are present in food ${ }^{[24]}$.M ore than 250 different food borne diseases have been described. M ost of these diseases are infections, caused by a variety of bacteria, viruses, and parasites that can be food-borne ${ }^{[13]}$. Other diseases are poisonings, caused by harmful toxins or chemicals that have contaminated the food, for example, poisonous mushrooms. These different diseases have many different symptoms, so there is no one"syndrome" that is a food borne illness ${ }^{[22]}$. However, the microbe or toxin enters the body through the gastrointestinal tract, and often causes the first symptoms there, so nausea, vomiting, abdominal cramps and diarrhoea are common symptoms in many food borne diseases ${ }^{[19]}$. Many microbes can spread in more than one way, so we cannot always know that a disease is food borne. However, the distinction matters, because public health authorities need to know how a particular disease spreads in order to take the appropriate steps to stop it. For example, Escherichia coli 0157:H7 infections can spread through contaminated food, contaminated drinking water, contaminated swimming water, and from toddler to toddler at a day care centre ${ }^{[15]}$. Depending on which means of transmission caused a case, the measures to stop other cases from occurring could range from removing contaminated food from stores, chlorinating a swimming pool, or closing a child day care centre ${ }^{[25]}$. 


\section{Materials and M ethods \\ Antibiotics Susceptibility Test}

Susceptibility of isolates to different antibiotics were tested following Kirby Bauer disc diffusion method using Muller Hinton Agar against selected antibiotics, namely Ampicillin $(25 \mu \mathrm{g})$, Chloramphenicol $(50 \mu \mathrm{g})$, Kanamycin $(30 \mu \mathrm{g})$, Streptomycin $(30 \mu \mathrm{g})$ and Tetracycline $(100 \mu \mathrm{g})(\mathrm{Hi}-$

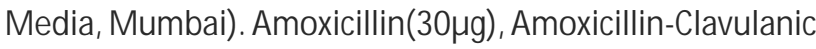
acid $(30 \mu \mathrm{g})$, Cefoxitin $(30 \mu \mathrm{g})$, Cefotaxime $(30 \mu \mathrm{g})$, Ceftriaxone $(30 \mu \mathrm{g})$, Cefuroxime $(30 \mu \mathrm{g})$, Ceftazidime (30 $\mu \mathrm{g})$, Gentamicin $(10 \mu \mathrm{g})$,$) , Ofloxacin (30 \mu \mathrm{g})$, Cloxacillin $(5 \mu \mathrm{g})$, Nitrofurantoin $(30 \mu \mathrm{g})$ Levofloxacin $(30 \mu \mathrm{g})$, Ciprofloxacin $(30 \mu \mathrm{g})$ (Oxoid, UK). Inhibition zone size was interpreted using standard recommendation of National Committee for Clinical Laboratory Standards [N.C.C.L., 2000] now known as Clinical Laboratory Standard Institute (CLSI) [C.L.S.I., 2005]

\section{Procedure For Performing The Disc Diffusion Test}

The growth method was performed as follow;

(1) At least three to five well isolated colonies of the same morphological type was selected from an agar plate culture. The top of each was touched with a loop, and the growth was transferred into a tube containing 4 to $5 \mathrm{ml}$ of a suitable broth medium.(2) The broth culture was incubated until it achieved or exceeded the turbidity of the $0.5 \mathrm{M}$ cFarland standards which tookup to sixhours.

\section{Inoculation of Test Plates.}

Optimally, within 15 minutes after adjusting the turbidity of the inoculum's suspension, a sterile cotton swab was dipped into the suspension. The swab was then rotated several times and pressed firmly on the inside wall of the tube above fluid level. This was done to remove excess inoculums from the swab.(2) The dried surface of a Mueller-Hinton agar was inoculated by streaking the swab over the entire sterile agar surface. This procedure was repeated by streaking two or more times, by rotating the plate approximately $60^{\circ} \mathrm{C}$ each time to ensure an even distribution of inoculums. As a final step. the rim of the agar was swabbed.(3) The lid was left ajar for some minutes to allow for any excess surface moisture to be absorbed before applying the drug-impregnated discs.

\section{Placement of Discs}

The predetermined battery of antimicrobial discs was dispensed onto the surface of the inoculated agar plate. Each disc was pressed down to ensure complete contact with the agar surface. Whether individually or with a dispensing apparatus, they must be distributed evenly so that they are no close than $24 \mathrm{~mm}$ from center to center. Ordinarily, no more than 12 discs should be placed on 150 $\mathrm{mm}$ plate, or more than five discs on a $100 \mathrm{~m}$ plate. Because some of the drug diffuses almost instantaneously, a disc should not be relocated once it has come into contact with the agar surface. Instead, place a new disc in another location on the agar.

The plates were then inverted and placed in an incubator set to $350 \mathrm{c}$ within 15 minutes after the discs are applied.

\section{Reading Plates and interpreting results}

After 16 to 18 hours of incubation, each plate was examined, the diameters of the zones of inhibition (as judged by the unaided eye) are measured, including the diameter of the disc.

Zones are measured to the nearest whole millimeter, using sliding calipers or a ruler, which is held on the back of the inverted Petri plate. The sizes of the zone of inhibition are interpreted by referring to the NCCL's table on Zone Diameter Interpretive Standards and Equivalent M inimal Inhibitory Concentration (MIC) Break points for Enterobacteriaceae.

\section{Plasmid Profile Analysis}

Plasmids are circular deoxyribonucleic acid molecules that exist in bacteria, usually independent of the chromosome. The study of plasmids is important to medical microbiology because plasmids can encode genes for antibiotic resistance or virulence factors. Plasmids can also serve as markers of various bacterial strains when a typing system referred to as plasmid profiling, or plasmid fingerprinting is used. In these methods, partially purified deoxyribonucleic acid species are separated according to molecular size by agarose gel electrophoresis. In a second procedure, plasmid deoxyribonucleic acid which has been cleared by 
restriction endonucleases can be separated by agarose gel electrophoresis and the resulting pattern of fragments was used to verify the identity of bacterial isolates. Because of the many species of bacteria, plasmid profile analysis has been used to investigate outbreaks of many bacterial diseases and to trace inter-and intra species spread of antibiotic resistance.

\section{Mechanism of plasmid profile analysis}

Plasmids were detected by a modified rapid method. Cells were grown in $3 \mathrm{ml}$ of L-broth overnight at $30^{\circ} \mathrm{C}$ to an optical density at $600 \mathrm{~mm}$ of 0.8 and pelleted by centrifugation $\left(5,700 \mathrm{rpm}, 4^{\circ} \mathrm{C}\right.$, for $7 \mathrm{~min}$ in a Sorvall SS34 rotor). The cell pellets were thoroughly suspended in $1 \mathrm{ml}$ of E buffer. The cells were then lysed by adding $2 \mathrm{ml}$ of lysing solution, which was mixed by brief agitation.

The solution was heated at $50{ }^{\circ} \mathrm{C}$ to $65^{\circ} \mathrm{C}$ for $20 \mathrm{~min}$ in a water bath, and $2 \mathrm{ml}$ volumes of phenolcholoform solution (1:1, vol/vol) were added. The solution was emulsified by shaking, and the emulsion was broken by centrifugation $\left(6,000 \mathrm{rpm}, 15 \mathrm{~min}, 4^{\circ} \mathrm{C}\right.$ IN A Sorvall SS34 rotor). Avoiding the precipitate at the interface, the upper aqueous phase was transferred to a screw cap tube by using a polyethylene Pasteur pipette (Ulster Scientific, Inc, Highland, N.Y). Sample was withdrawn directly for electrophoresis immediately. $35 \mathrm{pl}$ of sample was mixed on a square of parafilm "M " (American Can Company, Greenwich, Conn.) with $10 \mathrm{pl}$ of $0.25 \%$ bromocresol purple in $50 \%$ glycerol0.05 M Tris- acetate (pH7.9). To minimize sharing of large plasmids it is important that samples be withdrawn and transferred with Drummond 50-ud micropipettes and an Adams no 4555 suction apparatus (Becton, Dickinson \& Co., Rutherford, N.J. ) After centrifugation, the supernatant was subjected to agarose gel electrophoresis for the detection and sizing of plasmid DNA.

The organism were separated into two groups (i.e gram positive and gram negative) and the extraction mechanism for each was applied. Details are given below;

\section{Extraction of plasmidsfrom Gram positive bacteria}

The plasmids were extracted by growing the bacterial cellsovernight on Luria -Bertani medium supplemented with $50 \mu \mathrm{g} / \mathrm{mL}$ ampicillin. It was then centrifuged at 13,000 rpm for 2 minutes to pellet cells. $500 \mu \mathrm{L}$ of normal saline was added, vortex and pulse at 13,000 rpm for 10 seconds to wash cells. The supernatantwas removed and cells resuspended in $500 \mu \mathrm{L}$ of Tris (10mM)-EDTA (1mM)-Sucrose (50mM) buffer ( $\mathrm{pH} 8.0)$. Later $500 \mu \mathrm{L}$ Lysis buffer solution containing SDS (1\%) and Lysozyme $(2 \mathrm{mg} / \mathrm{mL})$ in Tris (10mM)- EDTA (1mM) buffer (pH 8.0) added. Then incubated at $37^{\circ} \mathrm{C}$ for 2 hours. The preparation was boiled at $95^{\circ} \mathrm{C}$ for 3 minutes and the suspension was neutralized by adding 3M KOAC (pH 5.2). Then the suspension wascentrifuged at $13,000 \mathrm{rpm}$ for 5 minutes. The upper layer was transfered into a new sterile Eppendorf tube. Twice the volume of absolute ethanol (95.5\%) was added and centrifuged at $10,000 \mathrm{rpm}$ for 5 minutes. The supernatant was decanted and pellet washed with $70 \%$ ethanol. Twice the volume of absolute ethanal was added and centrifuged and the pellet was dried in the air. The DNA pellet was re-dissolved in 40 $\mu \mathrm{L}$ of Tris-EDTA buffer ( $\mathrm{pH}$ 8.0). Then the purity of the DNA solution was assessed using nanodrop Spectrophotometer and the plasmid DNA samples were electrophoresed on $0.9 \%$ agarose at $70 \mathrm{~V}$ for $40 \mathrm{~min}$.

\section{Plasmid DNA Isolation from Gram Negative Bacteria (Alkaline Lysis method of Bimboimand Doly, 1979)}

$200 \mu$ l of buffer $1 \mathrm{~A}$ was added to cell pellet and vortex, and $400 \mu$ lysing solution. The test tubes were inverted20 times at room temperature. $300 \mu$ of ice cold buffer $2 B$ added, vortex and keep on ice for 30 minutes. Suspension centrifuged at 3,000xg for 15 minutes. To the supernatant, $700 \mu \mathrm{l}$ of chloroform was added and Vortex then centrifuged at $3,000 \mathrm{xg}$ for 10 minutes.To $500 \mu \mathrm{l}$ aqueous layer, $1 \mathrm{ml}$ of absolute ethanol was added and kept in ice for 1 hour, and again centrifuged at 3000xg for 30 minutes. Pellet was then washed with $70 \%$ ethanol, decanted and dried. Then $50 \mu$ l of buffer $3 \mathrm{C}$ wasadded to the pellet.

The composition of each buffer solution and lysing solution are given below; 
BUFFER 1A

400mM Tris

20mM NaEDTA

Acetic acid to $\mathrm{pH} 8.0$

BUFFER 3C

$10 \mathrm{mM}$ Tris

$2 \mathrm{mM} \mathrm{Na}_{2}$ EDTA

LYSINGSOLUTION

$4 \%$ SDS

$100 \mathrm{mM}$ Tris

Acetic acid to $\mathrm{pH} 8.0$

Plasmid DNA was extracted by alkaline lysis method with (Gram +ve) and without (Gram -ve) Lysozyme. Electrophoresis was done horizontally on 1\% agarose gel at 70V for 40 minutes, stained with ethidium bromide, visualized under UV light and photographed thereafter.

Sizes of DNAs were extrapolated based on the relative mobilities of $10 \mathrm{~kb}$ ladder DNA markers that were coelectrophoresed with the DNA samples.

\section{Results}

Table 1 shows the results obtained from the antibiotic sentivity test carried out, Table 2 shows the multiple resistance of bacterial isolates to antibiotics while Figure 1 shows the plasmid profiling of the isolates.

The antibiotics susceptibility testing of the isolated organism showed varied results (Table 1). Streptococcus sp. showed resistance to four antibiotics which are Cotrimoxazole, Nitrofurantoin, Tetracycline and Ofloxacin. Escherichia coli showed resistance to Amoxicillin, Tetracycline, Chloramphenicol and Augmentin. Proteus vulgaris showed multiple resistances to five antibiotics which are Augmentin, Nitrofurantoin, Amoxicillin, Cotrimoxazole and Nalidixic. The Staphylococcus sp. isolated showed multiple resistances to Cloxacillin, Erythromycin, Amoxicillin, Augmentin and Gentamicin. Shigella sp. was resistant to Amoxicillin and Augmentin. Bacillus sp. was resistant to Amoxicillin, Cotrimoxazole,

Table 1 : Antibiotics sensitivity pattern of isolated organisms

\begin{tabular}{|l|c|c|c|c|c|c|c|c|c|c|c|}
\hline Isolated organism & Amx & Cot & Nit & Gen & Nal & Ofl & Aug & Tet & Chl & Ery & Cxc \\
\hline Shigella sp & - & + & + & + & + & + & - & + & NA & NA & NA \\
\hline Escherichia coli & - & + & + & + & + & + & - & - & - & NA & NA \\
\hline Stretococcus sp & + & - & - & + & + & - & + & - & NA & NA & NA \\
\hline Bacillus sp & - & - & - & + & + & + & + & - & NA & NA & NA \\
\hline Staphylococcus & - & + & NA & - & NA & NA & - & + & ++ & - & - \\
\hline Proteus Vulgaris & - & - & - & + & - & + & - & - & NA & NA & NA \\
\hline Pseudomonas aeruginosa & - & + & + & - & + & + & - & - & NA & NA & NA \\
\hline
\end{tabular}

KEY : Amx =Amoxicillin, Cot=Cotrimoxazole, Nit=Nitrofurantoin, Gen=Gentamycin, Nal=Nalidixic, Ofl=Ofloxacin, Aug=Augmentin, Tet=Tetracycline, Chl=Chloramphenicol, Ery=Erythromycin, Cxc=Cloxacillin

stands for Resistant

+standsfor Sensitive
NA - Stands for Not Applicable +tstands for strongly sensitive

Table 2 : Multiple antibiotics resistanceof isolated organisms

\begin{tabular}{|l|c|l|}
\hline Bacterial isolates & Antibiotics range & $\begin{array}{l}\text { Antibiotics to which multiple } \\
\text { resistance was demonstrated }\end{array}$ \\
\hline Streptococcus sp. & $2-4$ & Cot, Nit, Ofl, Tet \\
\hline Staphylococcus aureus & $2-5$ & Amx, Gen, Aug, Ery, Cxc \\
\hline Proteus vulgaris & $2-6$ & Amx, Cot, Nit, Nal, Ofl, Aug \\
\hline Salmonella typhi & 2 & Amx,Aug \\
\hline Shigella sp. & 2 & Nal, Ery \\
\hline Escherichia coli & 3 & Amx, Tet, Chl \\
\hline $\begin{array}{l}\text { Pseudomonas } \\
\text { aeruginosa }\end{array}$ & $2-4$ & Amx, Gen, Aug, Tet \\
\hline
\end{tabular}

KEY : Amx =Amoxicillin, Cot= Cotrimoxazole, Nit= Nitrofurantoin, Gen= Gentamycin, Nal= Nalidixic, Ofl= Ofloxacin, Aug=Augmentin, Tet=Tetracycline, Chl=Chloramphenicol, Ery=Erythromycin, Cxc=Cloxacillin 
Gentamycin and Tetracycline. Another organism isolated is Pseudomonas aeruginosa which showed resistance to Amoxicillin, Augmentin, Gentamicin and Tetracycline.

\section{Discussion}

Antibiotics resistance among bacteria has been a major concern and a worldwide problem, particularly hospital bacterial pathogens which led to a number of hazards as well as benefits of antimicrobial therapy ${ }^{[13]}$.

All the test organisms used in this research showed multiple resistances to different antibiotics. Such response of the organism against the antibiotics indicates a possible role of plasmids in such resistance behaviour. The presence of multiple plasmids may support the high resistance profile against a range of antibiotic as plasmid borne resistance is common in many microbes. It is well reported that antibiotic resistance is often plasmid borne ${ }^{[46]}$. Proteus vulgaris exhibited the highest resistance to the antibiotics, with a value of six out of eleven antibiotics (54.5\%). Resistance of Proteus vulgaris against Cotrimoxazole and Nitrofurantoin was reported by ${ }^{[22]}$. Similar results were reported by ${ }^{[15]}$.

The high antibiotic resistance of Proteus vulgaris may be an indication of the resistance levels among the Enterobacteriaceae since indiscriminate ingestion of antibiotics provides selective pressure, leading to a higher prevalence of resistant bacteria ${ }^{[5]}$. Not only are these species potential causes of infections but also potential reservoirs of resistance genes that could be transferred to other bacterial pathogens. The high levels of ß-lactamase production and multi-drug resistance of the isolates are indications of an increase in the resistance menace reported by many studies ${ }^{[22]}$. Staphylococcus aureus, being the second highest most resistant pathogen in this research, is mostly dependent on the presence of plasmids for resistance. Plasmids are believed to play a very important role in mediating and transferring resistance to antibacterial drugs in the Staphylococcus population. They can be vectors of resistance genes, or these genes can be localized in discrete transposable elements of DNA called transposons, which are mobile and can move from one
DNA molecule to another. This can lead to the rapid spread of antibiotic resistance in a staphylococcus population, and explains the emergence of multi-resistant strains. Pseudomonas aeruginosa also exhibited a considerably high level of multiple resistances. This is in correlation with the report of ${ }^{[14]}$ that Pseudomonas. Aeruginosa is frequently resistant to many commonly used antibiotics. The multiple resistances shown by Escherichia coli to Amoxicillin, Chloramphenicol and Tetracycline agrees with the work of ${ }^{[8]}$, who reported multiple resistances of the organism to beta-lactam antibiotics. Five out of a total of seven test organisms (71.4\%) were resistant to Amoxicillin, while four organisms (57.1\%) were resistant to Augmentin. This agrees with the work of ${ }^{[1]}$. The high resistance observed for Amoxicillin and Tetracycline could be due to its high and prolonged usage and regular abuse in our society. Nalidixic, Chloramphenicol and Cloxacillin were the least resistant to (14.3\%), with one organism each. The use of antibiotics in primary agricultural production is also considered an important cause of antimicrobial resistance selection in bacteria that may subsequently be found on foodstuffs.

This finding is in agreement with the conclusion of some researchers that high percentage of many commonly encountered gram- positive and negative food borne pathogens have at least one and frequently multiple plasmids which may be responsible for their resistance to antibiotics ${ }^{[15]},{ }^{183]}$ and ${ }^{[22]}$

\section{Conclusion}

The overall result of this study shows that all isolates that are resistant to more than one antibiotics possess Plasmid. Though their sizes varies but all still showed the presence of plasmid which could be said to code for their resistance to the antibiotics.

Several studies had indicated plasmid as coding for the resistance factor ( $\mathrm{R}$ plasmid) which enables bacterial to resist antibiotics. Since presence of plasmid has been observed in all of these organisms, further molecular studies should be carried out to reveal the exact position of the plasmid and ascertain the exact plasmid responsible. 


\section{References}

1. Adeshina, G,.O., Jibo, S.D., Agu, V.E. (2012). Antibacterial Susceptibility Pattern of Pathogenic Bacteria Isolates from Vegetable Salad Sold in Restaurants in Zaria, Nigeria. J. Microbiol. Res. 2:5-11.

2. Al-Bahry, Saif N., Al-Mashani, Basma M., Elshafie, Abdulkadir E., Pathare, N. Al-Harthy, Asila H. (2006): Plasmid profile of antibiotic resistant Escherichia coli isolated from chicken intestines. Journal of the Alabama Academy of Science.

3. Archambault, M.,Jalbert, L.,Tremblay, C., Harel, J. (2008): Characterization of new genes encoding for acquired bacitracin resistance in Clostridium perfringens American Society of Microbiology conference p. 25

4. Barrow G.I. and R.K.A. Felthan (2003) Cowan and Steel's M anual for the Identification of Medical Bacteria. 3rd Ed. Cambridge University Press. Cambridge UK. 351-353.

5. Carattoli, A. (2008): Characterization of plasmids carrying antimicrobial resistance: American Society of Microbiology conference. p.24

6. CDC "Center for Disease Control and Prevention", (2002): National Antimicrobial Resistance Monitoring System for Enteric Bacteria Annual Report for 2000, CDC. Clinical Laboratory Standards Institute.

7. CDC "Center for Disease Control and Prevention". (2005) : Foodborne illnesses, Department of Health and Human services.

8. Chamot, E., Boffi, E.L., Amari, E. Rohner, P. (2003): Effectiveness of Combination antimicrobial therapy for Pseudomonas aeruginosa bacteremia. Journal of Antimicrobial Agents Chemotherapy. 47 (9): 2750-2764

9. Cotran, Ramzi, S., Kumar, Vinay, F, N., Robbins, S.L.,Abbas,A.K., (2005): Robbins and Cotran pathologic basis of disease. St.Louis, Mo: ElsevierSaunders. pp. 878.

10. Devirgiliis, C., Caravelli, A., Coppola, D., Barile, S., Perozzi, G. (2008): Antibiotic Resistanceand Microbial Composition Along the Manufacturing Process of Mozzarella Di BufalaCampana. International Journal of Food M icrobiology, 128(2):378-384.

11. Feglo P.K., Gbedema S.Y., Quay S.N.A., Adu-Sarkodie Y., and C. OpokuOkrah (2010). Occurrence, species distribution and antibiotic resistance of Proteus isolates: A case study at the Komfo Anokye Teaching Hospital (KATH) in Ghana. International Journal of Pharma Sciences and Research (IJPSR), 1(9): 347-352.

12. Fratamico, P. M. Bhunia, A. K. and Smith J. L. (2005): Textbook on FoodbornePathogens.Microbiology and Molecular Biology. 454 pp. Caister AcademicPress.

13. Geraldine, D., Brendan, K., Justine, F., James, J.S. (2011): Routine Diagnostic Tests For Food-Borne Pathogens, The National Food Centre

14. Keskin, O. and Arserim-Kaya, N.B., (2010): Aerobic Bacteria and Fungi Isolated from External Ear Canal of Healthy Dogs and the Antibiotic Susceptibility of Staphylococci. Journal of Animal Veterinary.
Advances 9 (3): 496-500

15. Lyskova, P.M., Vydrzalova, and M azurova J. (2007): Identification and antimicrobial susceptibility of bacteria and yeasts isolated from helthy dogs and dogs with otitis externa. J. Vet. M edical Animal 54: 559-563.

16. Newman M.J., Frimpong E., Asamoah-Adu A., and E. Sampane-Donkor (2006) Resistance to Antimicrbial Drugs in Ghana. The Ghanaian - Dutch collaboration for Health Research and Development, 1-6.

17. Ogunleye, A. O., Ajuwape, A. T. and Adetosoye, A. I. (2010): Infectious drug resistance plasmid study in Salmonella enterica isolates of domestic animals and lizards from some south western states of Nigeria. African Journal of Biotechnology Vol. 9(25), pp. 3726-3731

18. Ramesh, S., P. M anivasagan, S. Ashokkumar, G. Rajaram and P. M ayavu, (2010): Plasmidprofiling and multiple antibioticresistance of heterotrophic bacteria isolated frommuthupettai mangrove environment, southeast coast of India. Current Research in Bacteriology. pp3: 227-237

19. Rodrick, G. E. and R. H. Schmidt. (2003): Physiology and Survival of Foodborne PathogensinVarious Food Systems. In: Food Safety Handbook, R. H. Schmidt and G.E. Rodrick, (eds.).New York: John Wiley $\&$ Sons, Inc

20. Saleh A. Bahashwan and Hatem M. El Shafey (2013): Antimicrobial Resistance Patterns Of Proteus Isolates From Clinical Specimens. European Scientific Journal September 2013 edition vol.9, No.27 ISSN: $1857-7881$

21. Svara, F. and Rankin, D.J. (2011). The evolution of plasmid-carried antibiotic resistance. BMC Evol. Biol.11:130. (http://www. biomedcentral.com/14712148/11/130).

22. Thyagarajan, S.P. Dharmalingam, S., Rao, U.A., Jayaraman, G. (2003):Relationship of plasmid profilewith the antibioticSensitivity pattern of helicobacter pylori isolates fromPeptic ulcer diseasepatients in Chennailndian Journal of M edical M icrobiology.Vol. $21(4)$, pp 257-261

23. Thyagarajan, S.P., Ray, P., Das, B.K., Ayyagari, A., Khan,A.A Dharmalingam, S., Rao, U.A,Rajasambandam, P.,Ramathilagam, B., Bhasin, D., Sharma, M.P., Naik, S.R.,Habibullah, C.M. (2011):Geographic difference inantimicrobial resistance pattern of Helicobacterpylori clinicalisolates from Indian patients: amulticentric study. Journal of Gastroenterol Hepatol (inPress).

24. Willey, J. M., Sherwood, L. M., Woolverton, C. J. (2010): Microbiology. Prescott, Harvey and Klein's, Mc Graw-Hill Inc. Ed. 8th, pp891,986, 1032-1034.

25. Zulkifli, Y., Alitheen, N.B., Raha, A.R., Yeap, S. K., Marlina, S.R. and Nishibuchi, M. (2009): Antibiotic resistance and plasmid profiling of Vibrio parahaemolyticus isolated from cockles in Padang, Indonesia. International Food Research Journal. 16: 53-58 